Boise State University

ScholarWorks

$1-1-1998$

Body Condition and the Adrenal Stress Response in Captive American Kestrel Juveniles

Julie A. Heath

Boise State University

Alfred M. DuftyJr.

Boise State University 


\section{Body Condition and the Adrenal Stress Response in Captive American Kestrel Juveniles}

\author{
Julie A. Heath \\ Alfred M. Dufty, Jr.* \\ Department of Biology and Raptor Research Center, \\ Boise State University, Boise, Idaho 83725 \\ Accepted by G.K.S. 8/8/97
}

\begin{abstract}
We examined the adrenal response to handling stress of birds in different body conditions. In order to affect the birds' body condition, young (73-d old) female American kestrels (Falco sparverius) were maintained for 6 wk on one of three diets: a control diet (fed ad lib.) and two calorically restricted diets. To invoke a stress response, we removed birds from their cages and took repeated blood samples over the course of an hour. All birds responded to handling stress with an increase in plasma corticosterone, but control birds (in good body condition) showed a more rapid increase to maximum corticosterone levels, followed by a decrease. Both groups of foodrestricted birds had a slower rate of increase to maximum corticosterone levels and then maintained high corticosterone levels through $60 \mathrm{~min}$. These results suggest that birds in good physical condition respond more quickly to stressors and adapt physiologically to stressful situations more rapidly than do birds in poor physical condition. This difference may reflect the ability of birds in good condition to mobilize fat for energy, while birds in poor condition must mobilize protein (i.e., muscle).
\end{abstract}

\section{Introduction}

Corticosterone, a steroid hormone produced by the adrenal cortex, is the primary hormone secreted by birds in periods of acute stress (Siegel 1980; Harvey et al. 1984). Wingfield (1994) proposed that elevated plasma corticosterone levels are responsible for stimulating alternate metabolic pathways and behavior patterns in unpredictable (or stressful) conditions. These alter-

${ }^{\star}$ To whom correspondence should be addressed. E-mail: adufty@claven .idbsu.edu.

Physiological Zoology 71(1):67-73. 1998. (C) 1998 by The University of Chicago. All rights reserved. 0031-935X/98/7101-96104\$03.00 nate strategies allow birds to endure stressful situations, such as storms or restricted food availability. Behavioral and metabolic responses can include increased locomotor activity (Astheimer et al. 1992; Smith et al. 1994), decreased nocturnal oxygen consumption (Astheimer et al. 1992), lipogenesis (Harvey et al. 1984; Gray et al. 1990), increased food intake (Bray 1993), and increased energy availability resulting from protein catabolism (Gray et al. 1990; Wingfield et al. 1995).

While a rapid adrenocortical response is important in restoring homeostasis, chronically elevated corticosterone levels may be detrimental to a bird's physical condition. That is, prolonged exposure to high corticosterone could lead to excessive protein catabolism and irreversible muscle deterioration (Harvey et al. 1984). For example, dark-eyed juncos (Junco hyemalis) implanted with corticosterone undergo severe muscle atrophy (Gray et al. 1990). In addition, tonic high levels of corticosterone may inhibit a bird's ability to use fat stores for energy (Gray et al. 1990). Therefore, an efficient stress-response system would include a rapid rise in plasma corticosterone to stimulate alternate metabolic or behavior patterns, followed by a rapid recovery of corticosterone to baseline levels to avoid muscle deterioration and allow fat catabolism.

Age, social status, gender, season, and food availability can affect the corticosterone response (Schwabl et al. 1985, 1988; Stewart et al. 1988; Gray et al. 1990; Astheimer et al. 1992). For example, aged rats have reduced efficiency in the negative feedback system that is responsible for suppressing corticosterone production (Stewart et al. 1988). Furthermore, female and first-year male Eurasian blackbirds (Turdus merula) have higher circulating corticosterone levels than adult males during times of food restriction (Schwabl et al. 1985). Females and first-year males are subordinate to adult males, and subordinates may be more susceptible to nutritional stress, hence their higher corticosterone levels (Schwabl et al. 1985).

Physical condition influences susceptibility to nutritional stress and, therefore, may affect the adrenal response in many ways. Smith et al. (1994) found a significant negative relationship between body condition and maximum corticosterone levels in common diving petrels (Pelecanoides urinatrix) during calm weather. Birds in poor body condition may have higher baseline corticosterone levels than birds in good condition, an effect that would facilitate metabolism of protein for energy (see, e.g., Cherel et al. 1988). However, poor condition may affect the timing and extent of the adrenal response; that is, because of nutritional depletion, adrenal glands may be impaired and unable to produce or release corticosterone as 
quickly or effectively (Smith et al. 1994). Furthermore, chronic stress may produce changes in the number of glucocorticoid receptors (Meaney et al. 1989), and this could affect corticosterone production or the rate of the adrenocortical response.

Finally, birds in different body conditions may have different patterns of stress-response activation and recovery to baseline because of differences in their energy reserves. For example, during periods of restricted food availability, birds in good physical condition may have a greater chance of surviving because they possess abundant energy reserves in the form of well-supplied fat stores (Sharpiro and Weathers 1981; Blem 1990). In healthy birds faced with a stressful situation, increases in corticosterone stimulate alternate behavior (e.g., increased foraging; Wingfield 1994), and subsequent decreases in corticosterone would conserve muscle mass. Because birds in poor condition have reduced fat stores, corticosterone levels may remain elevated to catabolize protein for energy (Cherel et al. 1988).

In this study we examined the relationship between body condition and circulating plasma corticosterone in captive young American kestrels (Falco sparverius) using a standardized adrenocortical stress-response protocol (Wingfield et al. 1992). Our objectives were to determine if baseline plasma corticosterone levels differ in relation to body condition, maximum corticosterone levels differ in relation to body condition, rates of plasma corticosterone increase differ among birds in different body conditions, and body condition affects the temporal pattern of the adrenocortical stress response. Finally, in order to ascertain whether the changes in circulating corticosterone levels we measured in captive kestrels occur under more natural conditions, we determined plasma corticosterone titers in freeliving kestrels.

\section{Material and Methods}

\section{Examination of Corticosterone in Captive American Kestrels}

We collected American kestrels nestlings ( $n=28$; 23-25-d old) from nest boxes located near Shoshone, Idaho (elevation $=1,000 \mathrm{~m} ; 43^{\circ} 00^{\prime} \mathrm{N}, 114^{\circ} 30^{\prime} \mathrm{W}$ ). To control for possible effects of sex, we used only females. Birds were housed individually in wire mesh cages $(66 \times 66 \times 66 \mathrm{~cm})$ at Boise State University's animal care facility. Animals were isolated visually but not acoustically. Artificial light followed natural photoperiod (approximately 16L : 8D), and temperatures were maintained at $22.0^{\circ} \pm 2.0^{\circ} \mathrm{C}$. As part of another study, birds were fitted with pedometers ( 8 g; catalog no. 63-671, Radio Shack, Fort Worth, Tex.; see Ritchison et al. 1992) to measure locomotor activity, and blood samples $(300 \mu \mathrm{L})$ were collected once a week for $5 \mathrm{wk}$. It is possible that after repeated weekly blood sampling, attenuation in the response to the stressor may occur and affect baseline corticosterone levels. Over the 5-wk sampling period prior to this experiment, significant changes in baseline corticosterone levels occurred (J. A. Heath, unpublished data). This was in conjunction with the period of natal dispersal of free-living kestrels and may have reflected the proposed association between changes in plasma corticosterone secretion and dispersal behavior (Belthoff and Dufty 1997). However, baseline corticosterone levels in the present study were similar (i.e., within 1 SD) to baseline corticosterone levels obtained during the first week of blood sampling.

Kestrels reach adult weight $(120-140 \mathrm{~g})$ at fledging (Bird 1985), which occurs at approximately $30 \mathrm{~d}$ of age. We fed birds whole laboratory mice ad lib. until the birds reached $31 \mathrm{~d}$ of age, at which time we randomly assigned each bird to one of three diets. Ten birds continued to be fed ad lib. and were considered controls. We used the equation $(234.9 \times$ mass $\left.[\mathrm{kg}]^{0.75}\right) / 4.19$ (Fowler 1993) to determine daily requirements $(\mathrm{kJ} / 24 \mathrm{~h})$ of birds on a restricted diet. This diet ensured that birds would lose mass gradually and could be maintained at a lower mass after approximately $2 \mathrm{wk}$ (J. A. Heath, unpublished data). Nine birds received a moderately restricted diet $(90 \%$ of necessary caloric requirement). Once these birds lost $10 \%$ of their initial mass, they were maintained at that mass for the remainder of the 6-wk experimental period. An additional nine birds were kept on a severely restricted diet and received $80 \%$ of their daily caloric requirement. Once they lost $20 \%$ of their initial mass, they were maintained at that mass. Earlier work on captive kestrels has shown that a diet reduced to $80 \%$ of ad lib. is stressful in that it is likely to reduce the survival of fledglings (Lacombe et al. 1994).

When birds were $73 \mathrm{~d}$ of age (independent juvenile phase in free-living birds; J. A. Heath, personal observation), we collected $30-50 \mu \mathrm{L}$ of blood immediately after removing a bird from its cage (usually within $1 \mathrm{~min}$ ) and again at 5, 10, 30, and $60 \mathrm{~min}$. Total blood volume collected was $150-250 \mu \mathrm{L}$. Between samples, we put each bird in a cloth sack and placed it on a table. We collected blood between 0800 and 0900 hours to minimize time-of-day effects on circulating plasma corticosterone levels (Wingfield et al. 1992). We collected blood with microhematocrit tubes after puncturing the brachial vein with a 26-gauge needle. Tubes were sealed at one end with clay and within $20 \mathrm{~min}$ were centrifuged for $3 \mathrm{~min}$ at 2,000 rpm. Plasma was stored in plastic microcentrifuge tubes at $-20^{\circ} \mathrm{C}$ until analyzed 1 wk later.

\section{Examination of Corticosterone in Free-Living American Kestrels}

In 1994 and 1995, we collected blood from free-living kestrels at 22-25 d of age (late nestling phase; Bird 1985). We removed entire clutches from nest boxes located in Ada and Canyon counties, Idaho, and placed them in a 20 -L plastic bucket. We recorded sampling time for each bird beginning when the clutch was removed from the nest box and ending when the blood sample was collected. This differed from the laboratory 
protocol in that each bird was sampled only once. Furthermore, in the laboratory, birds were physically and visually limited by a cloth sack, whereas in the field, birds were held in a bucket, where they could move and see each other. From each nestling we collected $300-500 \mu \mathrm{L}$ of whole blood in heparinized Caraway tubes and stored them on ice. We returned each bird to the bucket until all of its siblings had been sampled, at which time we returned the entire clutch to the nest box. We separated the plasma within $3 \mathrm{~h}$ of collection and stored it at $-20^{\circ} \mathrm{C}$ until analyzed 1 mo later.

\section{Hormone Analyses}

Corticosterone levels were analyzed by radioimmunoassay (RIA) as described by Wingfield et al. (1992) and Smith et al. (1994). Plasma (15-25 $\mu \mathrm{L})$ was placed in test tubes with 375$385 \mu \mathrm{L}$ of distilled water (total vol. $=400 \mu \mathrm{L}$ ) and $20 \mu \mathrm{L}$ (approximately 2,000 cpm) of tritium-labeled corticosterone (used to calculate recovery values). After equilibrating overnight, we added $5 \mathrm{~mL}$ of freshly distilled dicholoromethane to all tubes to extract steroid hormones and stored tubes overnight at $4^{\circ} \mathrm{C}$. The organic (lower) phase was aspirated into test tubes, dried under nitrogen gas in a warm $\left(40^{\circ} \mathrm{C}\right)$ water bath, and resuspended in $550 \mu \mathrm{L}$ of phosphate-buffered saline. We pipetted $100 \mu \mathrm{L}$ of the organic phase into scintillation vials, added $4 \mathrm{~mL}$ of scintillant, mixed, and let them equilibrate overnight before counting to determine recovery values. For the RIA, we pipetted $200 \mu \mathrm{L}$ of sample into duplicate assay tubes. To each assay tube we added $100 \mu \mathrm{L}$ of labeled corticosterone and $100 \mu \mathrm{L}$ of corticosterone antiserum and let them equilibrate. To separate bound and free hormone, we added $0.5 \mathrm{~mL}$ of a dextran-coated charcoal solution. After $10 \mathrm{~min}$, samples were centrifuged at 2,000 rpm for $10 \mathrm{~min}$. We decanted the supernatant into scintillation vials and added $4 \mathrm{~mL}$ of scintillant. These were allowed to equilibrate overnight before counting to $2 \%$ accuracy or for $10 \mathrm{~min}$. As accuracy controls, we placed $500 \mathrm{pg}$ of corticosterone in each of two test tubes. Final readings for these samples were 549 and 677 pg (coefficient of variation $=56.13$ ).

\section{Experimental Design and Statistical Analyses}

Our experimental design was a two-factor mixed factorial, where diet was a between-groups factor and time (1-60 min) was a within-subjects factor. Prior to analysis by ANOVA, we examined the data in relation to ANOVA assumptions. Using an $F_{\max }$-test, we determined that the data were heteroscedastic $\left(F_{15,8}=27.01, P<0.05\right)$; therefore, we log-transformed them prior to analysis by ANOVA (Sokal and Rolhf 1995). We then performed a two-way (diet $\times$ time) repeated-measures ANOVA to examine the effects of diet and time on corticosterone.

We examined the relationship between rate of change in corticosterone levels and body condition with two different analyses. First, we compared the sample period in which birds on different diets reached their maximum corticosterone level using a Kruskal-Wallis test (Sokal and Rolhf 1995). Second, to determine whether differences in timing of maximum corticosterone levels were a function of different rates of increase, rather than a function of starting at different baseline levels, we performed another two-way (diet $\times$ time) repeated-measures ANOVA using percent change from baseline as the dependent variable. Finally, we used a MANOVA to compare corticosterone maxima, baseline corticosterone levels, and changes in mass among birds in the three treatment groups.

To examine the relationship between time and plasma corticosterone levels in free-living birds, we used a polynomial regression analysis after determining that the relationship was not linear. Because the process of fledging is related to corticosterone levels (Heath 1997), we used time to fledging as a covariate in this analysis. We report means \pm 1 standard error (SE) throughout.

There are two missing data points in our analyses. We could not collect blood from one severely food-restricted bird in the 60-min sample because of vasoconstriction. We also removed one outlier because the corticosterone level in this sample (control diet, 60-min sample) was more than twice the highest corticosterone value and approximately 5.5 standard deviations above the mean corticosterone value for that time period (Zar 1984).

\section{Results}

The diets affected body mass $\left(F_{2,25}=98.37, P=0.0001\right)$. Birds on the control diet gained an average of $4.6 \pm 4.17 \mathrm{~g}$ over the course of the experiment, while birds on the $90 \%$ and $80 \%$ food-restricted diets lost an average of $10.6 \pm 2.76 \mathrm{~g}$ and 17.2 $\pm 3.34 \mathrm{~g}$, respectively.

\section{Baseline and Maximum Corticosterone Levels}

We did not detect a difference in baseline corticosterone levels (Fig. $1 ; F_{2,25}=2.20, P=0.1316$ ) among the three groups of captive birds. In addition, maximum corticosterone levels did not differ among groups (Fig. $1 ; F_{2,25}=0.02, P=0.9833$ ).

\section{Rate of Adrenal Response}

Rate of onset of the adrenocortical stress response differed among groups (Fig. 2; Kruskal-Wallis $\chi^{2}=11.656$, $\mathrm{df}=2, P$ $=0.0029$ ). Three birds in good condition (control diet) exhibited peak corticosterone levels in the 5-min sample, and the remaining seven control birds peaked in the 10-min sample. Birds on the $90 \%$ diet were more variable, exhibiting peaks in the 5- and 10-min samples (three birds for each), as well as in the 30-min (one bird) and 60-min (two birds) samples. 


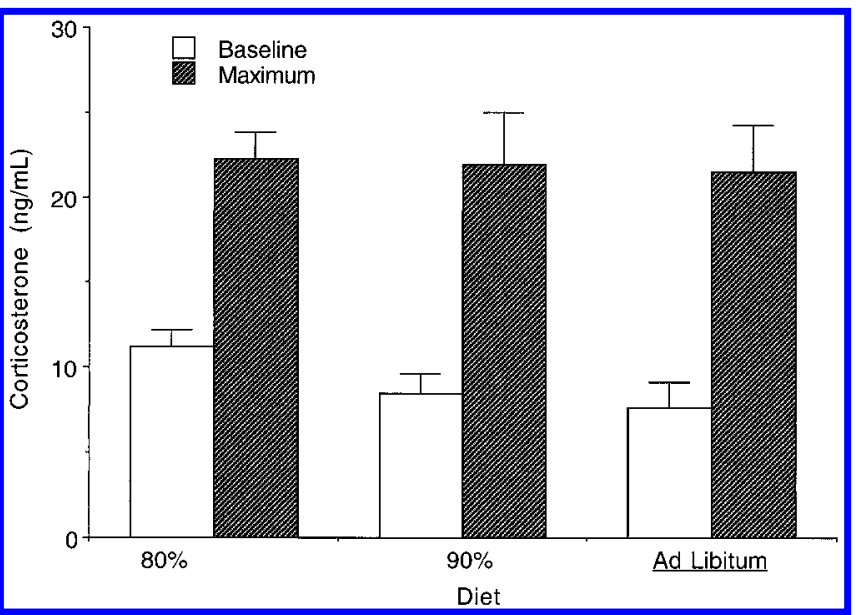

Figure 1. Baseline and maximum stress-induced plasma corticosterone levels (mean $\pm \mathrm{SE}$ ) in relation to diet. There were no significant differences among diet groups in either comparison.

Finally, only one bird on the $80 \%$ diet peaked as early as the 10 -min sample, while the rest peaked in the 30 - or 60 -min samples (four birds for each). Hence, control birds reached maximum corticosterone levels in the shortest amount of time. Indeed, pair-wise comparisons showed a significant difference in rate of increase between birds fed ad lib. and birds on the $90 \% \operatorname{diet}(P=0.03)$ and birds on the $80 \% \operatorname{diet}(P=0.0005)$ in the 5-min sample. No difference was detected in the rate of increase for the $80 \%$ and $90 \%$ groups $(P=0.1456)$.

\section{Temporal Corticosterone Pattern}

The overall shapes of the response curves also differed among the three treatment groups; that is, there was a significant diet

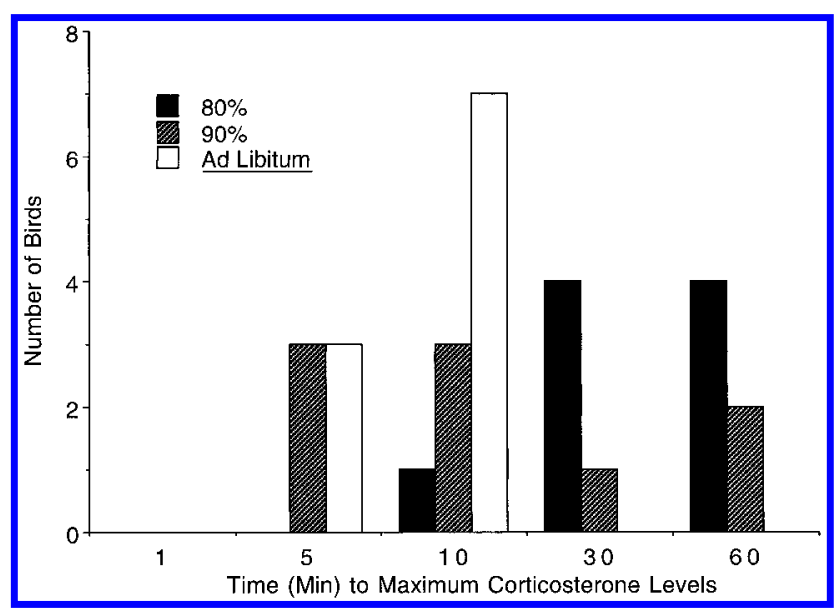

Figure 2. Sample period in which birds on different diets reached maximum plasma corticosterone levels. Birds on different diets reached maximum corticosterone levels in different sample periods $(P=0.0029)$.

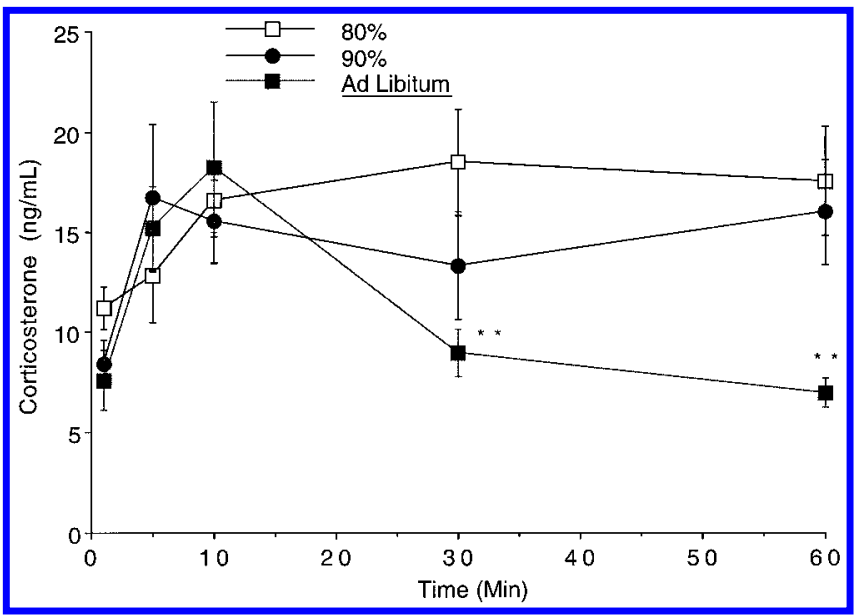

Figure 3. Changes in plasma corticosterone levels (mean \pm SE) over time (diet $\times$ time, $P=0.0046$ ). Significant differences between ad lib. and food-restricted diets are represented by ${ }^{\star \star}(P$ $=0.0001)$.

$\times$ time interaction (Fig. $3 ; F_{8,98}=3.03, P=0.0045$ ). All groups exhibited increased plasma corticosterone during the first 5-10 min, but birds in good condition reduced their corticosterone values at 30 and $60 \mathrm{~min}$. Birds fed at the $90 \%$ level maintained elevated plasma corticosterone levels from 5 to $60 \mathrm{~min}$. Birds fed at the $80 \%$ level also maintained elevated corticosterone titers. Several birds in this group increased their plasma corticosterone levels throughout the sampling period, exhibiting maximal plasma corticosterone values at $60 \mathrm{~min}$ (Fig. 2). Thus, food-restricted birds did not show the same reduction in corticosterone levels that was seen in control birds.

\section{Corticosterone Levels in Free-Living Kestrels}

Free-living juveniles showed a pattern of circulating corticosterone similar to birds maintained on the control diet (Fig. 4). Unlike data for captive birds, field data were not sequential. Therefore, the resulting curve is based on continuous data. There was a significant relationship between time and corticosterone levels (polynomial regression: $y=5,767.923$ $\left.+1,142.01 x-36.852 x^{2} ; r^{2}=0.219, P=0.0478\right)$. Free-living birds increased plasma corticosterone levels until $15 \mathrm{~min}$, at which time corticosterone levels began to decrease.

\section{Discussion}

During fasting or extreme food deprivation, corticosterone levels increase (Klandorf and Harvey 1984) and stimulate protein catabolism. Although control birds had the lowest average baseline corticosterone levels, we did not detect a significant difference in baseline corticosterone levels among the three treatment groups. However, the power of our comparison was low (power $=0.27$ ), which indicates that we had a relatively 


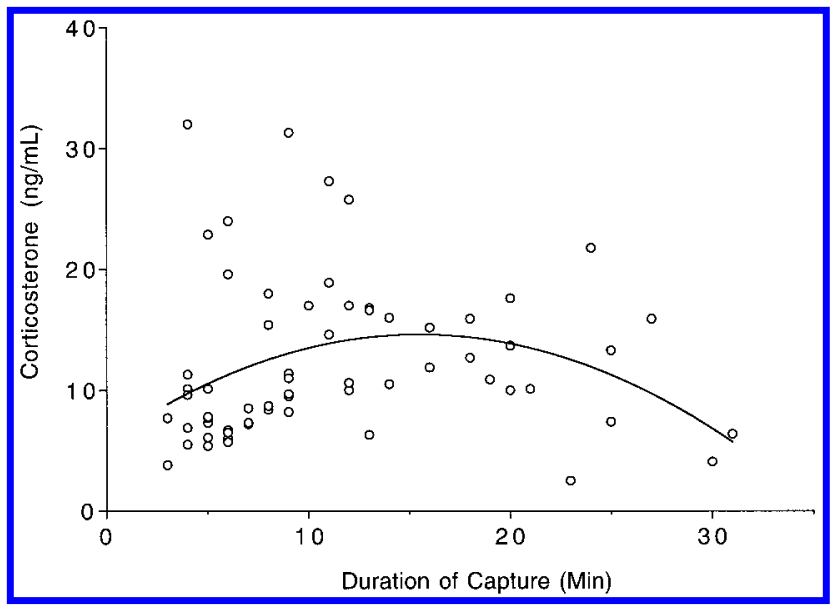

Figure 4. Plasma corticosterone levels in free-living birds in relation to time until the blood sample was taken. There was a significant relationship between time and plasma corticosterone level $\left(r^{2}\right.$ $=0.219, P=0.0478$ ).

high chance $(63 \%)$ of failing to reject the null hypothesis if it were false; that is, a Type II error could have gone undetected. Indeed, the high and variable corticosterone levels in foodrestricted birds may indicate that some of these birds were in a state of caloric depletion that required protein catabolism to meet energetic requirements (Cherel et al. 1988).

Although birds at $90 \%$ and $80 \%$ of normal body mass were restricted nutritionally, maximum corticosterone levels were not significantly different among birds in the three groups (see also Wingfield et al. 1992; Smith et al. 1994). Therefore, it appears that chronically food-restricted birds have the same potential maximal adrenal output as birds fed ad lib. Thus, all of the birds, irrespective of level of nutritional restriction, may have had the potential to react to stress with the same intensity (Smith et al. 1994).

Despite achieving similar maxima, American kestrels in different physical condition differed in their rate of increase of plasma corticosterone levels. Birds on the control diet exhibited a rapid response to handling stress, while food-restricted birds took significantly longer to reach maximum corticosterone values. It is possible that food restriction caused relatively continuous adrenal stimulation, resulting in inhibition of the hypothalamo-pituitaryadrenal axis through negative feedback regulation and changes in glucocorticoid receptor levels (e.g., Rarey et al. 1995). This may have contributed to the slower response to subsequent stress in food restricted birds than in control birds.

The rapid increase in circulating corticosterone levels exhibited by birds in good physical condition was followed by a reduction of corticosterone toward baseline. Several previous studies on the temporal pattern of corticosterone in free-living birds have noted similar increases in corticosterone levels during the first 10-30 min, although these elevated levels generally are maintained at the 60-min sample (e.g., Wingfield et al.
1992; Smith et al. 1994). Declines in corticosterone similar to those reported here also have been reported (e.g., domestic fowl, Gallus domesticus [Edens and Siegel 1976; Freeman and Flack 1980]; western screech-owl, Otus kennicotti [Dufty and Belthoff 1997]). These latter studies all involved captive birds, which suggests that the decline may be related to captivity. That is, declines in corticosterone in well-fed American kestrels may have resulted from daily handling over the 6-wk period of captivity. Indeed, rats handled regularly early in life exhibit a more rapid termination of the glucocorticoid stress response than do nonhandled rats when subsequently challenged with a stressor (e.g., Meaney et al. 1989). However, free-living kestrels that had been handled only once prior to sampling responded similarly to captive birds in good condition, reducing the likelihood that the results are due to handling. Although the free-living birds were nestlings and were $6 \mathrm{wk}$ younger than the captive birds, their hypothalamo-pituitary-adrenal axis appears to be developed at this age and even may play a role in fledging behavior (Heath 1997).

The pattern of corticosterone secretion cannot be explained as adaptation to the 6 wk of handling and weekly blood sampling that occurred prior to testing. Captive birds in all three treatment groups were handled similarly, yet only the control birds exhibited a decline to basal corticosterone levels. Furthermore, Dufty and Belthoff (1997; A. M. Dufty and J. R. Belthoff, unpublished data) have found that juvenile western screechowls, tested after only a few days of captivity and in the absence of regular handling, also exhibit baseline corticosterone titers and a decline in corticosterone from maximal levels similar to that found in juvenile owls handled and bled repeatedly.

Kestrels in good body condition responded to stress differently than those in poor condition. A rapid increase in corticosterone levels triggers locomotor behavior (Astheimer et al. 1992) and stimulates movement away from stressful situations (Smith et al. 1994). Also, a rise in plasma corticosterone may inhibit production of other steroid hormones (Greenberg and Wingfield 1987) and further change behavior.

A rapid recovery of corticosterone toward baseline levels would free the animals from the catabolic effects of corticosterone, through reduced synthesis and enhanced breakdown of protein (see, e.g., Bowes et al. 1996). Furthermore, kestrels in good condition have more fat stores than those fed restricted diets (Lacombe et al. 1994), and energy retrieval strategies during stressful situations should differ, depending on body condition (Cherel et al. 1992). Although higher body mass does not always mean more fat reserves (Thompson et al. 1993), chronically limited food availability causes birds to mobilize fat, then protein, for energy (Cherel et al. 1988). Birds in poor condition may have little fat and may depend primarily on protein catabolism for energy in emergencies. Therefore, prolonged high levels of corticosterone may stimulate locomotor and foraging activity (Astheimer et al. 1992) and mobilize protein energy reserves through muscle catabolism (Gray et al. 1990). 
The 30-50- $\mu \mathrm{L}$ blood samples represent a larger percentage of total blood volume in birds of lower body mass and could add a hemorrhagic component to the handling stress. However, birds with one-sixth the body mass of kestrels have been subjected to the stress-response protocol with larger blood volumes than applied here and have shown no apparent hemorrhagic effects (see, e.g., Astheimer et al. 1994). Thus, we feel that differences in loss of blood volume contribute little, if anything, to our results.

Body mass initially declines rapidly with food restriction, although birds adapt to prolonged food restriction by reducing their metabolic rate (Cherel et al. 1988). Our experimental birds, tested after $6 \mathrm{wk}$ of food restriction, no longer were losing weight (J. A. Heath, unpublished data), which suggests that they had adapted to reduced food availability. It would be interesting to compare hormonal responses early in food restriction (i.e., during the period of rapid body mass reduction) with those we obtained after $6 \mathrm{wk}$ on a restricted diet.

Our results indicate that body condition affects the adrenocortical stress response. Birds in better body condition responded to capture stress with a faster rise in corticosterone levels than birds in poor body condition. In addition, birds in good body condition had decreased corticosterone levels after 30-60 min, while birds in poor condition maintained elevated circulating corticosterone levels. Further research examining the metabolic effects of elevated corticosterone levels during periods of stress and the relationships between body condition and the adrenal stress response would be illuminating.

\section{Acknowledgments}

D. Edgerton helped with collection of samples and maintenance of birds in captivity. We thank Drs. J. Belthoff and N. Clum for suggestions on the manuscript. J. Belthoff and Dr. J. Munger contributed to the statistical analysis of the data. K. Steenhof and M. Kochert provided valuable technical support. This study was supported by the Raptor Research Technical Assistance Center, National Biological Service, a grant from the Bergstrom Memorial Research Fund to J.A.H., and a Faculty Research Associateship to A.M.D.

\section{Literature Cited}

Astheimer L.B., W.A. Buttemer, and J.C. Wingfield. 1992. Interactions of corticosterone with feeding, activity and metabolism in passerine birds. Ornis Scand. 23:355-365.

- 1994. Gender and seasonal differences in the adrenocortical response to ACTH challenge in an Arctic passerine, Zonotrichia leucophrys gambelii. Gen. Comp. Endocrinol. 94:33-43.

Belthoff J.R. and A.M. Dufty, Jr. 1997. Corticosterone, body condition, and locomotor activity: a model for dispersal in screech-owls. Anim. Behav. (in press).
Bird D.M. 1985. Evaluation of the American kestrel (Falco sparverius) as a laboratory research animal. Pp. 3-9 in J. Archibald, J. Ditchfield, and H.C. Roswell, eds. Proceedings of the 8th Symposium of the International Council for Laboratory Animal Science/Canadian Association for Laboratory Animal Science, Vancouver, 1983. Gustav Fischer, Stuttgart and New York.

Blem C.R. 1990. Avian energy storage. Curr. Ornithol. 7:59113.

Bowes S.B., N.C. Jackson, D. Papachristodoulou, A.M. Umpleby, and P.H. Sönksen. 1996. Effect of corticosterone on protein degradation in isolated rat soleus and extensor digitorum longus muscles. J. Endocrinol. 148:501-507.

Bray M.M. 1993. Effect of ACTH and glucocorticoids on lipid metabolism in the Japanese quail, Coturnix coturnix japonica. Comp. Biochem. Physiol. 105A:689-696.

Cherel Y., J.-P. Robin, A. Heitz, C. Calgari, and Y. Le Maho. 1992. Relationships between lipid availability and protein utilization during prolonged fasting. J. Comp. Physiol. 162B:305-313.

Cherel Y., J.-P. Robin, and Y. Le Maho. 1988. Physiology and biochemistry of long-term fasting in birds. Can. J. Zool. 66:159-166.

Dufty A.M., Jr. and J.R. Belthoff. 1997. Corticosterone and the stress response in young western screech-owls: effects of captivity, gender, and activity period. Physiol. Zool. 70:143149.

Edens F.W. and H.S. Siegel. 1976. Modification of corticosterone and glucose responses by sympatholytic agents in young chickens during acute heat exposure. Poult. Sci. 55:17041712.

Fowler M.E. 1993. Session 5: Feeding and Nutrition of Animals in Rehabilitation Centers. International Wildlife Rehabilitation Society Skill Seminar, California.

Freeman B.M. and I.H. Flack. 1980. Effects of handling on plasma corticosterone concentrations in the immature domestic fowl. Comp. Biochem. Physiol. 66A:77-81.

Gray J.M., D. Yarian, and M. Ramenofsky. 1990. Corticosterone, foraging behavior, and metabolism in dark-eyed juncos, Junco hyemalis. Gen. Comp. Endocrinol. 79:375-384.

Greenberg N. and J.C. Wingfield. 1987. Stress and reproduction: reciprocal relationships. Pp. $389-426$ in D.O. Norris and R.E. Jones, eds. Reproductive Endocrinology of the Adrenal Cortex. Academic Press, London.

Harvey S., J.G. Phillips, A. Rees, and T.R. Hall. 1984. Stress and adrenal function. J. Exp. Zool. 232:633-645.

Heath J.A. 1997. Corticosterone levels during nest departure of juvenile American kestrels. Condor 99:806-811.

Klandorf H. and S. Harvey. 1984. Adrenocortical function in fasted-refed birds. Boll. Zool. 51:353-357.

Lacombe D., D.M. Bird, and K.A. Hibbard. 1994. Influence of reduced food availability on growth of captive American kestrels. Can. J. Zool. 72:2084-2089. 
Meaney M.J., D.H. Aitken, V. Viau, S. Sharma, and A. Sarrieau. 1989. Neonatal handling alters adrenocortical negative feedback sensitivity and hippocampal type II glucocorticoid receptor binding in the rat. Neuroendocrinology 50:597-604.

Rarey K.E., K.J. Gerhardt, L.M. Curtis, and W.J.F. ten Cate. 1995. Effects of stress on cochlear glucocorticoid protein: acoustic stress. Hear. Res. 82:135-138.

Ritchison G., J.R. Belthoff, and E.J. Sparks. 1992. Dispersal restlessness: evidence for innate dispersal by juvenile eastern screech owls? Anim. Behav. 43:57-65.

Schwabl H., M. Ramenofsky, I. Schwabl-Benzinger, D.S. Farner, and J.C. Wingfield. 1988. Social status, circulating levels of hormones, and competition for food in winter flocks of the white-throated sparrow. Behaviour 107:107121.

Schwabl H., J.C. Wingfield, and D.S. Farner. 1985. Influence of winter on endocrine state and behavior in European blackbirds (Turdus merula). Z. Tierpsychol. 68:244-252.

Sharpiro C.J. and W.W. Weathers. 1981. Metabolic and behavioral responses of American kestrels to food deprivation. Comp. Biochem. Physiol. 68A:111-114.

Siegel H.S. 1980. Physiological stress in birds. BioScience 30:529-533.

Smith G.T., J.C. Wingfield, and R.R. Veit. 1994. Adrenocortical response to stress in the common diving petrel, Pelecanoides urinatrix. Physiol. Zool. 67:526-537.

Sokal R.R. and F.J. Rolhf. 1995. Biometry: The Principles and Practice of Statistics in Biological Research. W. H. Freeman, New York.

Stewart J., M.J. Meaney, D. Aitken, L. Jensen, and N. Kalant. 1988. The effects of acute and life-long food restriction on baseline and stress-induced serum corticosterone levels in young and aged rats. Endocrinology 123:1934-1941.

Thompson C.F., J.E.C. Flux, and V.T. Tetzlaff. 1993. The heaviest nestlings are not necessarily the fattest nestlings. J. Field Ornithol. 64:426-432.

Wingfield J.C. 1994. Modulation of the adrenocortical response to stress in birds. Pp. 520-528 in K.G. Davey, R.E. Peter, and S.S. Tobe, eds. Perspectives in Comparative Endocrinology. National Research Council of Canada, Ottawa.

Wingfield J.C., K.A. O’Reilly, and L.B. Astheimer. 1995. Modulation of the adrenocortical responses to acute stress in Arctic birds: a possible ecological basis. Am. Zool. 35:285-294.

Wingfield J.C., C.M. Vleck, and M.C. Moore. 1992. Seasonal changes in the adrenocortical response to stress in birds of the Sonoran Desert. J. Exp. Zool. 264:419-428.

Zar J.H. 1984. Biostatistical Analysis. Prentice-Hall, Englewood Cliffs, N.J. 